\title{
LAS PRETENSIONES EN EL PROCESO CONTENCIOSO ADMINISTRATIVO
}

\author{
PERCy SALAS FERRO*
}

\begin{abstract}
Resumen
La pretensión es una de las instituciones centrales del proceso contencioso administrativo porque incide en su inicio, desarrollo y culminación. En el presente artículo el autor aborda, desde una perspectiva teórico-práctica, los aspectos fundamentales de cada una de las pretensiones que se pueden plantear en el proceso contencioso administrativo; entre ellas, la pretensión de nulidad o ineficacia; la pretensión de reconocimiento o restablecimiento del derecho; la pretensión de declaración de contraria a derecho y cese de una actuación material; la pretensión de cumplimiento, y, la pretensión de indemnización. Con el propósito de contribuir a la adecuada formulación y evaluación de cada una de las pretensiones indicadas, se plantean algunos casos prácticos al final del trabajo.
\end{abstract}

Palabras clave: Pretensión - Pretensiones procesales - Proceso contencioso administrativo - Pretensiones en los procesos administrativos.

\begin{abstract}
The Claim is one of the central institutions of the contentious administrative proceeding since it affects its commencement, development and culmination. In this article, the author addresses the fundamental aspects, from a theoretical and practical perspective of each of the claims proposed in an administrative contentious proceeding such as the claim for annulment or nullity, the claim for the acknowledgement or reestablishment of the law, the claim for a statement contrary to law and the cessation of a material act, the claim for fulfillment and the claim for compensation. A few practical cases are included at the end of this paper aimed at contributing to the suitable formulation and evaluation of each one of the referred claims or petitions.
\end{abstract}

Key words: Claim - Procedural Claims - Contentious - Administrative Proceeding - Claims in administrative proceedings.

\section{Sumario}

1.- Introducción. 2.- La pretensión y otros conceptos previos. 2.1.- Concepto, características y elementos de la pretensión. 2.2.- Acción, pretensión y demanda. 2.3.- Pretensión y plena jurisdicción. 3.- Pretensión de nulidad o ineficacia. 3.1.- Causales de nulidad del acto administrativo. 3.2.- Efectos de la pretensión en la sentencia. 3.3.- Agotamiento de la vía administrativa, plazo y vía procedimental. 4.- Pretensión de reconocimiento o restablecimiento del derecho. 4.1.- Actuaciones contra las que se plantea. 4.2.- Efectos en la sentencia. 4.3.- Agotamiento de la vía previa, plazo y vía procedimental.

\footnotetext{
* Juez Especializado Titular en lo Contencioso Administrativo de la Corte Superior de Justicia de Lima - Poder Judicial del Perú. Profesor de la Academia de la Magistratura.
} 
Percy Salas Ferro - Las pretensiones en el proceso contencioso administrativo

5.- Pretensión de declaración de contraria a derecho y cese de una actuación material. 5.1.- Actuación contra la que se plantea. 5.2.- Efectos en la sentencia. 5.3 Agotamiento de la vía previa, plazo para impugnar y vía procedimental. 6.Pretensión de cumplimiento. 6.1.- Actuaciones contra las que se plantea. 6.2.Efectos en la sentencia. 6.3.- Agotamiento de la vía administrativa, plazo para impugnar y vía procedimental. 7.- Pretensión de indemnización. 8.- Resumen - Ideas fuerza. 9.- Conclusiones. 10.- Casos prácticos. 11.- Bibliografía.

El proceso contencioso administrativo tiene dos objetivos exclusivos:

1. Controlar si en su actuación la administración se somete a la ley, y,

2. Garantizar tutela judicial efectiva a los derechos e intereses legítimos de los ciudadanos

Eduardo García de Enterría Democracia, Jueces y Control de la Administración

\section{INTRODUCCIÓN}

En el presente trabajo abordaremos el tema de las pretensiones que se pueden plantear en el proceso contencioso administrativo - PCA. Se trata de una de las instituciones más importantes del PCA, pues incide en su inicio, desarrollo y culminación.

En la primera parte del artículo haremos referencia a algunos conceptos básicos que nos permitirán entender el contenido de la institución y desarrollar sistemáticamente cada una de las pretensiones. Las pretensiones de las que nos ocuparemos se encuentran recogidas en el artículo $5^{\circ}$ de la Ley 27584, Ley que Regula el Proceso Contencioso Administrativo, y son las siguientes: 1. La pretensión de nulidad o ineficacia, 2. La pretensión de reconocimiento o restablecimiento del derecho, 3 . La pretensión de declaración de contraria a derecho y cese de una actuación material, 4. La pretensión de cumplimiento, y, 5. La pretensión de indemnización.

A lo largo del trabajo desarrollaremos cada una de las pretensiones en base a un esquema que esencialmente permite conocer las actuaciones administrativas impugnables vinculadas a cada pretensión, su contenido, sus alcances, sus efectos en la sentencia, la necesidad de agotamiento de la vía previa, el plazo para impugnar y la vía procesal en que se tramita. 
Las siguientes interrogantes facilitarán nuestro acercamiento al tema de las pretensiones en el PCA y nos permitirán asimilar mejor las ideas y los planteamientos que se formulen en la presente contribución. En ese sentido, proceda a leerlas, reflexione sobre ellas, no intente tener una respuesta acabada y téngalas presente durante la lectura del trabajo.

1. ¿Qué es la pretensión y cuál es la función que cumple dentro del PCA?

2. ¿Sólo pueden plantearse pretensiones contra los actos administrativos?

3. ¿Puede el juez adoptar medidas, incluso no solicitadas, para satisfacer las pretensiones?

Finalmente, cabe indicar que es propósito del presente trabajo contribuir a la adecuada formulación y evaluación de cada una de las pretensiones que se pueden plantear en el PCA. Con dicho propósito, en la parte final del artículo, se han incorporado algunos casos para la aplicación práctica de los conocimientos desarrollados.

\section{LA PRETESIÓN Y OTROS CONCEPTOS PREVIOS}

Antes de iniciar el análisis de cada una de las pretensiones que pueden plantearse en el PCA, las mismas que se encuentran recogidas en el artículo $5^{\circ}$ de la Ley 27584, es necesario conocer algunos conceptos e ideas previas.

\subsection{Concepto, características y elementos de la pretensión}

Con el propósito de abordar adecuadamente el estudio de este capítulo, es necesario manejar desde el inicio algún concepto de pretensión. Al respecto, el destacado procesalista español Jaime GUASP DELGADO considera que la pretensión procesal "... es una declaración de voluntad por la que se solicita una actuación de un órgano jurisdiccional frente a persona determinada y distinta del autor de la declaración". Añade que la pretensión es una "declaración petitoria" que contiene el derecho reclamado y a través de ella "se expone lo que el sujeto quiere"1.1. $^{2}$.

Por su parte, el profesor Hernando Devis HeCHANDíA, entiende la pretensión como "...el fin concreto que el demandante persigue, es decir, las declaraciones que pretende se hagan en la sentencia". Precisa que se trata de una "...declaración de

1 GUASP, Jaime. «Derecho Procesal Civil». $4^{\mathrm{a}}$ ed. Tomo I. Revisada y actualizada a la legislación vigente por Pedro Aragonés. Madrid: Civitas, 1998, p. 206. 
Percy Salas Ferro - Las pretensiones en el proceso contencioso administrativo

voluntad del demandante para que se sujete o vincule al demandado en determinado sentido y para ciertos efectos jurídicos concretos mediante una sentencia"2.

Para el procesalista argentino Lino PALACIO, la pretensión es “...el acto en cuya virtud se reclama ante un órgano jurisdiccional y frente a una persona distinta, la resolución de un conflicto suscitado entre dicha persona y el autor de la reclamación. Dicho acto suministra, precisamente, la materia alrededor de la cual el proceso se inicia, desarrolla y se extingue"3.

Como puede observarse, la pretensión resulta ser una institución fundamental del proceso que consiste en la petición concreta que se hace a un órgano jurisdiccional para que ampare la postura del proponente en relación a una controversia o un asunto de su interés. Es una declaración petitoria en torno a la cual gira el desarrollo de todo el proceso. Precisamente por ello, la pretensión termina siendo reconocida como el objeto del proceso.

Como se ha indicado, la pretensión para ser tal contiene un pedido concreto del pretensor al órgano jurisdiccional porque considera que el derecho reclamado le pertenece. Tales pedidos en el caso del proceso contencioso administrativo pueden ser: La declaración de nulidad o ineficacia de un acto administrativo, el reconocimiento o restablecimiento de un derecho, la declaración de contraria a derecho y el cese de actuaciones materiales ilegítimas, la realización de una actuación debida, el otorgamiento de una indemnización, etc.

De las ideas expuestas, como puede desprenderse, lo que distingue o define a la pretensión son fundamentalmente tres características: 1) El llamado a la autoridad jurisdiccional para que resuelva un conflicto en determinado sentido, 2) La petición concreta efectuada para que se le reconozca, se efectivice o restablezca un derecho, 3) Que tal petición se formule respecto de una tercera persona con la cual se tiene una controversia.

Finalmente, resulta oportuno señalar que la pretensión está integrada por dos elementos: 1) Su objeto y, 2) Su razón. El primero de ellos representa el efecto jurídico que se quiere alcanzar y, el segundo, el fundamento fáctico y jurídico que respalda la petición ${ }^{4}$. El objeto de la pretensión es el pedido que se formula (petitum) y su razón son los argumentos que fundamentan el pedido (causa petendi).

\footnotetext{
2 Devis EchandíA, Hernando. Nociones Generales de Derecho Procesal Civil. Madrid: Aguilar, 1966, p. 216.

3 PAlacio, Lino. Manual de Derecho Procesal Civil. 14ª ed. Buenos Aires: Abeledo-Perrot, 1998, p. 94.

4 Hinostroza Minguez, Alberto. Proceso Contencioso Administrativo. Lima: Grijley, 2010, p. 302.
} 


\subsection{Acción, pretensión y demanda}

Para efectuar un estudio adecuado de la pretensión es necesario, en segundo lugar, distinguir los conceptos de acción, pretensión y demanda.

En efecto, atendiendo a lo desarrollado por la doctrina más reconocida, cabe precisar que la acción y la pretensión son dos categorías vinculadas pero diferentes. Al respecto, ya el insigne procesalista italiano Piero Calamandrei, concebía a la acción como el "...recurso con el que el ciudadano invoca, en su propio favor, la fuerza pública del Estado...". Es decir, la entendía como “...la facultad (...) de dirigirse al Estado para obtener justicia contra el obligado: Al faltar el voluntario cumplimiento del obligado, el titular del derecho se dirige al Estado a fin de que como garante de la observancia del derecho, convierta la obligación en sujeción" ${ }^{\prime \prime}$.

Más recientemente, MONTERO AROCA ha señalado que la acción es "...el derecho a la actividad jurisdiccional", es decir, el derecho "... a poner en movimiento la actividad jurisdiccional del Estado"6.

Desde otra perspectiva, Jorge Peyrano define la acción como "...un derecho subjetivo público, abstracto, autónomo de que goza toda persona -física o jurídicapara postular el ejercicio de la actividad jurisdiccional"7.

Como ya se ha indicado, la pretensión por su parte, es la petición concreta que se hace a un órgano jurisdiccional para que ampare la postura del proponente en relación a una controversia o un asunto de su interés. Es una declaración petitoria fundamentada en torno a la cual gira el desarrollo de todo el proceso, razón por la cual se le reconoce como el objeto del mismo.

Sobre la base de los conceptos y definiciones reproducidos en los párrafos precedentes, lo que en principio cabe señalar es que la acción es un derecho abstracto por la cual cualquier ciudadano puede poner en marcha la actividad jurisdiccional del Estado, mientras que la pretensión es una petición concreta formulada por un demandante específico con el propósito de que el órgano jurisdiccional resuelva el conflicto a su favor o le reconozca el derecho reclamado.

\footnotetext{
5 CAlamandrei, Piero. «Instituciones de Derecho Procesal Civil», Vol. I. (Traducción de la segunda edición italiana por Santiago Sentís Melendo). Buenos Aires: Ediciones Jurídicas Europa América, 1962, p. 231.

6 Montero Aroca y otros. «Derecho Jurisdiccional I». 17 a ed. Valencia: Tirant lo Blanch, 2009, p. 259.

7 Peyrano, Jorge. «Derecho Procesal Civil de Acuerdo al C.P.C. Peruano». Lima: Ediciones Jurídicas, 1995, p. 15.
} 
En ese sentido, la acción es un derecho a la tutela jurisdiccional, que existe incluso antes de la iniciación del proceso, mientras que la pretensión es una acto, una petición concreta, específica, que está contenida en la demanda, que constituye el objeto del proceso y, que en palabras de Lino PALACIO, es "... la materia alrededor de la cual el proceso se inicia, desarrolla y extingue".

En relación a la distinción entre acción y pretensión, el magistrado Jorge Peyrano señala: "A diferencia de la acción que es un derecho, la pretensión procesal (...) es una manifestación de voluntad a través de la cual alguien reclama algo ante el órgano jurisdiccional y contra otro. La pretensión es algo que se hace (declaración de voluntad) no que se tiene (derecho de acción). La pretensión -insistimos- no es un derecho sino un simple acto de voluntad exteriorizado mediante la presentación de la demanda en ejercicio del derecho de acción"

Finalmente, cabe añadir que la acción siendo una manifestación del derecho a la tutela jurisdiccional, permite que la pretensión sea interpuesta ante el órgano jurisdiccional.

De otro lado, también es necesario establecer algunas diferencias entre demanda y pretensión. Al respecto Lino Palacio entiende la demanda como "...un mero acto de iniciación procesal"9. En el mismo sentido se pronuncia Jaime Guasp ${ }^{10}$.

En nuestro medio el jurista Juan Monroy Gálvez define la demanda como "...un acto jurídico procesal (...) que es una declaración de voluntad a través de la cual el pretensor expresa su pedido de tutela jurídica al Estado y, a su vez, manifiesta su exigencia al pretendido"11.

Como puede observarse, existen significativas diferencias entre pretensión y demanda. La pretensión constituye una petición concreta que formula el pretensor para que el órgano jurisdiccional se pronuncie a su favor en relación al demandado, mientras que la demanda es un acto procesal que activa o da inicio al proceso. La pretensión, que es una declaración petitoria fundamentada, por lo general está contenida en la demanda, por su parte la demanda se materializa a través de la presentación de un documento que contiene la petición específica en que consiste la pretensión.

\footnotetext{
8 PeYRANO. op. cit. pp. 23 y 24.

9 PAlacio. op. cit. p. 95.

10 GUASP. op. cit. p. 206.

11 Monroy GÁlveZ, Juan. «La Formación del Proceso Civil Peruano». $3^{a}$ ed. Lima: Communitas, 2010, p. 235.
} 
Para distinguir mejor entre acción, pretensión y demanda es necesario precisar lo siguiente: La acción es un "derecho cívico" que permite acudir a los órganos jurisdiccionales para formular una petición concreta y determinada (pretensión). El acto concreto que permite ejercitar la acción y activar la maquinaria judicial es la demanda. La demanda se materializa a través de la presentación de un documento que por lo general contiene la pretensión. Por estas razones ese documento también toma el nombre de demanda

En relación a los vínculos y diferencias entre estos conceptos, Jaime GUASP, señala lo siguiente: "Concebido por el Estado el poder de acudir a los tribunales de justicia para formular pretensiones: derecho de acción, el particular puede reclamar cualquier bien de la vida, frente a otro sujeto distinto de un órgano jurisdiccional: pretensión procesal, iniciando para ello, mediante un acto específico: demanda, el correspondiente proceso, el cual tendrá como objeto aquella pretensión"12.

Bien, hasta aquí nos hemos referido a los conceptos de pretensión, acción y demanda, desde una perspectiva general. Corresponde ahora ocuparnos específicamente de la pretensión procesal que se plantea en el proceso contencioso administrativo.

Se ha señalado que la pretensión en general es la declaración de voluntad por la cual se formula una petición concreta al órgano jurisdiccional frente a una persona determinada y distinta del autor de la declaración. Sin embargo, la pretensión procesal administrativa tiene ciertas características que la distinguen de las demás pretensiones procesales. En ese sentido, la pretensión procesal administrativa es aquella que deduce un administrado frente a la administración pública ${ }^{13}$.

Al respecto, cabe anotar que este concepto admite una excepción que se presenta en el caso de los procesos de lesividad, en los cuales la pretensión la plantea la administración pública frente a los administrados a los que se les habría reconocido derechos de manera irregular.

Dejando a salvo la excepción indicada, mediante la pretensión procesal administrativa se reacciona ante una actividad de la administración pública sujeta al Derecho Administrativo o ante una actuación material a la que le faltaría la cobertura de un acto sujeto al derecho administrativo. Atendiendo a

\footnotetext{
12 GUASP. op. cit. pp. 205 y 206.

13 Cfr. GonZÁlez PéreZ, Jesús. «Manual de Derecho Procesal 1 Administrativo». $3^{a}$ ed. Madrid: Civitas, 2001, pp. 211 y 212.
} 
ello, cabe anotar que también la actuación que se le pide al órgano jurisdiccional a través de la pretensión está fundada en Derecho Administrativo ${ }^{14}$.

En ese sentido, la pretensión procesal administrativa es una declaración de voluntad que se plantea ante un órgano jurisdiccional efectuando una petición concreta contra una actuación presuntamente irregular de una entidad pública, regulada por el derecho administrativo. Es una declaración petitoria que se formula con el propósito que se ampare la postura del administrado en relación a la controversia con la administración pública. En torno a esta declaración petitoria gira el desarrollo de todo el proceso, razón por la cual la pretensión es el objeto del proceso contencioso administrativo.

\subsection{Pretensión y plena jurisdicción}

Tradicionalmente los administrados recurrían ante el Poder Judicial pretendiendo o requiriendo la declaración de nulidad de un acto de la administración que consideraban lesivo y afectado de vicios. Con lo cual el órgano jurisdiccional solo podía examinar la regularidad formal del acto administrativo impugnado, sin poder pronunciarse sobre el conflicto de fondo o sobre los derechos subjetivos del demandante.

Con la consolidación del principio del debido proceso y, fundamentalmente de la tutela jurisdiccional efectiva, ha emergido una nueva concepción respecto a los alcances del $\mathrm{PCA}^{15}$. Superando los límites del dogma revisor, la idea de la plena jurisdicción, basada en el debido proceso y la tutela jurisdiccional efectiva, permite al administrado solicitar la tutela de la generalidad de sus derechos subjetivos lesionados por la administración. Igualmente, permite al juez, no solo revisar la legalidad de la actuación administrativa, sino, pronunciarse sobre el conflicto de fondo, es decir, sobre los derechos subjetivos del administrado realmente afectados, reconociéndolos, restableciéndolos $\mathrm{y}$ adoptando todas las medidas necesarias para garantizar su efectiva satisfacción ${ }^{16}$.

\subsection{Pretensión, proceso y sentencia}

La pretensión, entendida como la petición concreta de tutela, es el elemento central del proceso, es su objeto y, además, determina los alcances de la

\footnotetext{
14 Cfr. GONZÁLEZ PÉREZ. op cit. 213.

15 Huapaya Tapia, Ramón. «Tratado del Proceso Contencioso Administrativo». Lima: Jurista Editores, 2006, p. 730.

16 Congreso de la RepúblicA. «Exposición de Motivos del Proyecto de Ley que Regula el Proceso Contencioso Administrativo». Diario Oficial “El Peruano", edición del 05/07/2001.
} 
sentencia. En función a la pretensión se desenvuelve el proceso, de ella depende el inicio, el desarrollo, la actividad probatoria y también la decisión del proceso.

Teniendo como base las nociones y conceptos formulados, podemos ahora entrar de lleno al estudio de cada una de las pretensiones que se pueden plantear en el proceso contencioso administrativo, las mismas que se encuentran recogidas en el artículo $5^{\circ}$ del TUO.

\section{PRETENSIÓN DE NULIDAD O INEFICACIA}

En nuestro ordenamiento todo acto administrativo se presume válido, conforme al precepto recogido en el artículo $9^{\circ}$ de la Ley 27444, Ley del Proceso Administrativo General - LPAG. En efecto, el referido dispositivo precisa: "Todo acto administrativo se considera válido en tanto su pretendida nulidad no sea declarada por autoridad administrativa o jurisdiccional, según corresponda".

No es objeto del presente estudio ocuparnos de la declaratoria administrativa de nulidad, sino de declaratoria judicial de nulidad.

Entonces, frente a un acto administrativo que se presume válido, pero que un administrado considera que lo agravia, la ley ha previsto un mecanismo procesal para conseguir su declaratoria judicial de nulidad. Es decir, para derrotar la presunción de validez.

Ese medio procesal es precisamente la pretensión de nulidad, parcial o total, recogida en el artículo $5^{\circ}$, numeral 1, de la ley 27584 , que dispone:

"En el proceso contencioso administrativo podrán plantearse pretensiones con el objeto de obtener lo siguiente: ...

1. La declaración de nulidad, total o parcial o ineficacia de actos administrativos".

Pero en concreto, ¿Qué significa declarar judicialmente la nulidad de un acto administrativo? Judicialmente, claro está, significa que exista pronunciamiento de un órgano del Poder Judicial en el marco de un proceso contencioso administrativo. Específicamente, la declaratoria de nulidad de un acto administrativo significa dejar sin efecto tal acto por haber incurrido en alguna de las causales de nulidad ${ }^{17}$.

\footnotetext{
17 Normas Legales. «Guía Práctica de Impugnación Judicial de Acciones Administrativas». Lima: Gaceta Jurídica, 2009, p. 34.
} 
Percy Salas Ferro - Las pretensiones en el proceso contencioso administrativo

El profesor Ramón HUAPAYA TAPIA, señala que el contenido de la pretensión recogida en el artículo $5^{\circ}$, numeral 1 , de la Ley 27584 , es el pedido específico para que se declare la nulidad de un acto administrativo por las causas tasadas en el artículo $10^{\circ}$ de la Ley 27444, Ley del Procedimiento Administrativo General. Agrega que:

“... la pretensión de nulidad de actos administrativos, tendrá como contenido la invocación objetiva de que se declare la invalidez de un acto administrativo aquejado de un vicio insubsanable, que debe ser reprimido judicialmente por el juzgador mediante la declaración judicial de nulidad"18.

De la definición referida, fácilmente pueden identificarse tanto el objeto como la razón de la pretensión administrativa. El objeto o petitum, es la invocación objetiva que se declare la nulidad, mientras que la razón o causa petendi se configura por el hecho que la administración ha incurrido en un comportamiento que constituye una causal de nulidad del acto administrativo.

En efecto, para declarar la nulidad de un acto administrativo debe verificarse que en su emisión se haya incurrido en alguno de los vicios o causales que la ley expresamente ha identificado.

\subsection{Causales de nulidad del acto administrativo}

Como se ha señalado, la pretensión recogida en el inciso 1 del artículo $5^{\circ}$ de la Ley 27584, implica la petición al juez correspondiente de la jurisdicción contencioso administrativa, que declare la nulidad del acto administrativo impugnado. Para efectuar tal declaración, lo que el juzgador debe hacer es verificar si el acto emitido por la administración está afectado de una causal de nulidad. Las causales de nulidad son afectaciones graves al acto administrativo que lo descalifican y lo privan de efectos por haber contravenido el ordenamiento jurídico. La ley que regula el Procedimiento Administrativo General, Ley 27444, señala expresamente en su artículo $10^{\circ}$, cuales son las causales de nulidad. Entre las causales señaladas por el indicado artículo, tenemos:

"3.1 La contravención a la Constitución, las leyes o a las normas reglamentarias.

3.2 El defecto o la omisión de alguno de los requisitos de validez. Salvo que se presente alguno de los supuestos de conservación del acto administrativo.

3.3 Los actos expresos o los que resulten como consecuencia de la aprobación automática o por silencio administrativo positivo, por los que se adquiera

\footnotetext{
${ }_{18}$ Huapaya. op. cit. p. 764.
} 
Percy Salas Ferro - Las pretensiones en el proceso contencioso administrativo

facultades o derechos, cuando son contrarios al ordenamiento jurídico, o cuando no se cumplen con los requisitos, documentación y trámites esenciales para su adquisición.

3.4 Los actos administrativos que son constitutivos de infracción penal, o que se dicten como consecuencia de la misma."

Como entre las causales de nulidad del acto administrativo se señala el defecto o la omisión de alguno de los requisitos de validez del acto administrativo, es necesario conocer también cuáles son esos requisitos de validez del acto administrativo.

\subsection{Requisitos de validez del acto administrativo}

El acto administrativo, como declaración de una entidad destinada a producir efectos, debe cumplir con determinadas condiciones. Esas condiciones, son exigencias básicas, insustituibles e imprescindibles, que de no verificarse el acto no cumple su finalidad, es decir, no surte efectos ni regula la relación entre la administración y el administrado.

Como hemos visto, la invalidez siempre implica nulidad. Por ello la pretensión de nulidad del administrado puede basarse en la ausencia de uno de los requisitos de validez del acto administrativo. Siendo ello así, es necesario conocer cuáles son esos requisitos de validez del acto administrativo, los mismos que ha sido recogidos en el artículo $3^{\circ}$ de la LPAG; entre ellos tenemos a los siguientes:

\section{a. La competencia}

El acto administrativo debe ser emitido por el órgano facultado en razón de la materia, territorio, grado, tiempo o cuantía.

b. Objeto o contenido

El acto administrativo debe expresar claramente su respectivo objeto, es decir, aquello que decide, declara o certifica, de manera que determine inequívocamente sus efectos jurídicos. El objeto o contenido debe ajustarse al ordenamiento jurídico.

c. Finalidad pública

El acto administrativo debe perseguir las finalidades de interés público que conforme al ordenamiento debe cumplir el órgano emisor.

d. Motivación

El acto administrativo, debe expresar las razones que lo fundamentan. Deberá señalar de forma clara y expresa todos los hechos probados relevantes para el caso específico, así como las razones jurídicas que justifican el acto adoptado. 


\section{e. Procedimiento regular}

Para su emisión, el acto administrativo debe observar el procedimiento previsto. Se refiere no solo a las reglas que rigen su emisión en estricto, sino a la observancia de las reglas del debido procedimiento durante todas las etapas del procedimiento administrativo al que está vinculado.

\subsection{Efectos de la pretensión en la sentencia}

Como hemos señalado, la pretensión es el elemento eje del proceso contencioso administrativo y como tal incide en el propio contenido de la sentencia y en los alcances y efectos de la misma.

En ese sentido, el artículo $41^{\circ}$, inciso 1, del TUO de la Ley 27584, en su primer párrafo, señala: "La sentencia que declare fundada la demanda podrá decidir en función de la pretensión planteada lo siguiente:... La nulidad, total o parcial o ineficacia del acto administrativo impugnado, de acuerdo a lo demandado".

\subsection{Agotamiento de la vía administrativa, plazo y vía procedimental}

Tratándose de la impugnación de un acto administrativo, el planteamiento de esta pretensión exige el agotamiento de la vía administrativa previa.

El plazo para impugnar planteando la pretensión de nulidad, es de tres meses, contados desde el día siguiente de notificado el acto que agota la vía administrativa (artículo 19${ }^{\circ}$, inciso 1, del TUO).

La vía procedimental que corresponde para plantear y sustanciar esta pretensión es la del procedimiento especial (artículo $28^{\circ}$ del TUO).

\section{PRETENSIÓN DE RECONOCIMIENTO O RESTABLECIMIENTO DEL DERECHO}

Es en esta pretensión, en la que se pone en evidencia la nueva concepción que orienta al PCA. En efecto, esta pretensión no solo se dirige contra un acto administrativo sino contra cualquier actuación administrativa que vulnere los derechos o intereses del administrado. Permite que de manera efectiva se tutele todos los derechos o intereses concretos de los administrados. Viabiliza la plena jurisdicción en la medida que permite al juez reconocer o restablecer los derechos subjetivos de los administrados y disponer que se adopten todas las medidas que sean necesarias para el reconocimiento y restablecimiento de la situación jurídica lesionada (satisfacción plena). 
Percy Salas Ferro - Las pretensiones en el proceso contencioso administrativo

Esta pretensión se encuentra recogida en el numeral 2 del artículo $5^{\circ}$ de la Ley 27584, cuyo texto establece que en el Proceso Contencioso Administrativo podrán plantearse pretensiones con el objeto de obtener lo siguiente:

“2. El reconocimiento o restablecimiento del derecho o interés jurídicamente tutelado y la adopción de las medidas o actos necesarios para tales fines."

En la actividad de la administración no solo se presentan actos administrativos sino otras actuaciones que vulneran los derechos de los administrados y que la pretensión nulificante, antes examinada, no se encuentra en capacidad de proteger.

Precisamente, con el propósito de tutelar los derechos subjetivos lesionados con actuaciones distintas al acto administrativo, es que surge esta pretensión general y pluricomprensiva, denominada también pretensión tutelar.

Como se ha señalado, la pretensión bajo comentario tiene por objeto el reconocimiento o restablecimiento del derecho del administrado-demandante.

El planteamiento de la pretensión de reconocimiento, como es lógico, presupone el desconocimiento o la negativa de la administración de atribuir un derecho que el administrado considera le corresponde. En otras palabras, la administración adopta una actitud que niega, refuta o rechaza un derecho o interés del administrado. Puede por ejemplo no reconocerle su derecho a registrar una marca, a ser titular de un permiso de pesca, a contar con una licencia de funcionamiento, a participar en un concurso público de proveedores, a acceder a un servicio público, a ejercer las facultades que le corresponden como titular de una concesión minera, a la devolución de un pago en exceso, al goce vacacional, al pago de la CTS o de una bonificación, etcétera.

Por su lado, el planteamiento de la pretensión de restablecimiento, presupone la vulneración de un derecho ya reconocido. La vulneración puede producirse, recortando, restringiendo, privando o anulando los derechos de los que gozaba un administrado. La administración en el ejercicio de sus funciones podría afectar o vulnerar indebidamente diversos derechos del administrado, así por ejemplo, su derecho al aprovechamiento de un bien o servicio otorgado en concesión, a preservar su marca, a la regularidad o continuidad del servicio eléctrico, a la inscripción legítima de un título, al mantenimiento de una exoneración tributaria, a mantener vigente su licencia de conducir, etcétera. 
Frente a tales actos, es decir, a la negativa de reconocimiento o a la privación de un derecho ya reconocido, el legislador ha previsto las pretensiones recogidas en el artículo $5^{\circ}$, numeral 2 , de la Ley 27584 , de manera que la autoridad judicial reconozca o reestablezca los derechos negados o lesionados del administrado.

\subsection{Actuaciones contra las que se plantea}

Hemos señalado que las pretensiones de reconocimiento y de restablecimiento son pluricomprensivas, es decir pueden plantearse contra una generalidad de actuaciones de la administración.

De las actuaciones administrativas recogidas en el artículo 4 de la Ley 27584, la pretensión del reconocimiento procede contra:

a) El silencio administrativo, la inercia y cualquier omisión de la administración pública (artículo $4^{\circ}$, inciso 2).

b) Las actuaciones y omisiones relativas a la contratación estatal (artículo $4^{\circ}$, inciso 5$)$.

c) Las actuaciones administrativas sobre el personal de la administración pública (artículo $4^{\circ}$, inciso 6).

En cambio, la pretensión de restablecimiento procede, por lo general, contra las actuaciones materiales; así, se plantea contra:

a) La actuación material que no se sustenta en acto administrativo (artículo $4^{\circ}$, inciso 3).

b) La actuación material de ejercicio indebido de actos (artículo $4^{\circ}$, inciso 4).

c) Las actuaciones u omisiones relativas a la contratación estatal en las que produzcan vulneraciones.

d) Las actuaciones contra el personal en los que se produzcan privaciones o vulneraciones.

Finalmente, cabe señalar que, teniendo en cuenta las particularidades de cada caso, las pretensiones de reconocimiento o restablecimiento pueden ser formuladas ya sea de manera independiente o de manera acumulada a la pretensión de nulidad.

\subsection{Efectos en la sentencia}

Planteada la pretensión de reconocimiento o restablecimiento, el juez al momento de emitir una sentencia favorable tendrá que pronunciarse conforme lo establece el artículo $41^{\circ}$, inciso 2 del TUO, es decir, disponiendo: 
Percy Salas Ferro - Las pretensiones en el proceso contencioso administrativo

"El restablecimiento o reconocimiento de una situación jurídica individualizada y la adopción de cuantas medidas sean necesarias para el restablecimiento o reconocimiento de la situación jurídica lesionada, aún cuando no hayan sido pretendidas en la demanda".

\subsection{Agotamiento de la vía previa, plazo y vía procedimental}

En base a lo dispuesto en el artículo $218^{\circ}$ de la Ley del Procedimiento Administrativo General - LPAG, y la disposición genérica de agotamiento obligatorio, contenida en el artículo $20^{\circ}$ del TUO, se ha ido consolidando en la práctica judicial el agotamiento previo de la vía administrativa cuando se plantean las pretensiones de reconocimiento y restablecimiento.

Tratándose de pretensiones mediante las cuales puede impugnarse diversas actuaciones administrativas, el plazo para formular las pretensiones de reconocimiento o restablecimiento tendría que estar en función de la actuación que se impugne. Sin embargo, en nuestro medio el legislador ha preferido establecer un plazo uniforme para casi todas las actuaciones, estableciendo un plazo de tres meses contados desde el día siguiente del acto materia de impugnación. No obstante ello, para el caso del silencio administrativo, la inercia y cualquier omisión de la administración, no debe calcularse plazo alguno (artículo $20^{\circ}$ del TUO).

La vía procedimental a usarse cuando se plantea la pretensión de reconocimiento y restablecimiento, es la vía del procedimiento especial, conforme lo dispone el artículo $28^{\circ}$ del TUO.

\section{PRETENSIÓN DE DECLARACIÓN DE CONTRARIA A DERECHO Y CESE DE UNA ACTUACIÓN MATERIAL}

Como puede advertirse, esta pretensión surge como consecuencia de que la administración ha perpetrado una actuación material de consecuencias nefastas para el administrado sin contar con el título o acto administrativo que la respalde. Se trata de una vía de hecho que de manera grosera quebranta el principio de legalidad ${ }^{19}$.

La pretensión bajo comentario contenida en el artículo $5^{\circ}$ inciso 3 de la Ley 27584, constituye una garantía contra las actuaciones arbitrarias de la

\footnotetext{
19 PERRINO, Pablo. «La pretensión Procesal Administrativa como Objeto del Proceso Contencioso Administrativo». En Juan Carlos Cassagne (Dir.), Tratado de Derecho Procesal Administrativo, tomo I, (pp. 409-436). Buenos Aires: La Ley, 2007, p. 429.
} 
Percy Salas Ferro - Las pretensiones en el proceso contencioso administrativo

administración que, transgrediendo los límites legales y sin contar con el título que le habilita, pasa a la vía de los hechos y ejecuta una lesión contra los derechos o intereses del administrado.

Frente a tales agresiones materiales, el legislador ha previsto en el artículo $5^{\circ}$ inciso 3 de la Ley 27584, la pretensión procesal mediante la cual el administrado afectado puede solicitar:

"La declaración de contraria a derecho y el cese de una actuación material que no se sustente en acto administrativo".

Como se puede advertir, ante el planteamiento de tal pretensión el juez, si resuelve ampararla, declara que la actuación impugnada es contraria a derecho. Contraria a derecho significa que es una actuación material de la administración que transgrede el ordenamiento jurídico, es decir las normas legales, disposiciones reglamentarias, normas y precedentes constitucionales, procedimientos, principios, precedentes administrativos, etcétera.

Se trata de una declaración que pone en evidencia la ilicitud de la actuación de la administración. Sin embargo, la pretensión no se limita a solicitar al juez una declaración que finalmente podría terminar siendo un pronunciamiento sin efectos concretos para detener la arbitrariedad y los perjuicios. En efecto, la pretensión bajo comentario, además de la declaración de contraria a derecho, persigue el cese de la actuación material ilícita que no se sustenta en acto administrativo.

Ello, significa que la pretensión no solo exige la declaración de ilegalidad, sino que compromete al juez a disponer el cese, la terminación, la extinción de la actuación material arbitraria; lo que, sin duda, constituye una garantía concreta y efectiva, respecto de las actuaciones ilegales y arbitrarias en las que la administración puede incurrir.

$\mathrm{Al}$ respecto, cabe poner en evidencia que este mecanismo de protección tan concreto y puntual no es sino la consecuencia de la nueva concepción que se maneja en el PCA, en el sentido de procurar la tutela efectiva de los derechos e intereses del administrado.

\subsection{Actuación contra la que se plantea}

Como ya lo hemos señalado, toda pretensión se relaciona con una actuación impugnable. Atendiendo a ello, mediante la pretensión bajo comentario se 
impugna la actuación administrativa contenida en el inciso 3 del artículo $4^{\circ}$ de la Ley 27584, que se refiere a la "actuación material que no se sustenta en acto administrativo".

\subsection{Efectos en la sentencia}

Ya hemos indicado que la pretensión incide en lo que se va a disponer en el fallo. Teniendo en cuenta ello, el legislador ha establecido, cómo debe pronunciarse el juez cuando resuelve amparar la pretensión de declaración de contraria a derecho y cese de una actuación material que no se sustente en acto administrativo.

Al respecto, el artículo $41^{\circ}$ del TUO ha señalado que en una sentencia estimatoria de esta pretensión el juez dispondrá: "La cesación de la actuación material que no se sustente en acto administrativo y la adopción de cuanta medida sea necesaria para obtener la efectividad de la sentencia, sin perjuicio de poner en conocimiento del Ministerio Público el incumplimiento para el inicio del proceso penal correspondiente, y la determinación de los daños y perjuicios que resultan de dicho incumplimiento".

Respecto a este dispositivo, es necesario destacar que se trata de una de las normas en la que se evidencia más claramente la materialización del principio de tutela jurisdiccional efectiva y de la facultad de plena jurisdicción que se le reconoce al juez. En efecto, en aplicación de tales preceptos el juzgador puede disponer toda medida que sea necesaria para hacer cesar la actuación material arbitraria e incluso para compensar por los daños y perjuicios sufridos por los afectados con la actuación material irregular. Se trata pues, de hacer cumplir las decisiones jurisdiccionales, pero, fundamentalmente, de proscribir la arbitrariedad en el ejercicio de la función pública, de proteger concreta y satisfactoriamente al administrado y de hacer efectiva la justicia.

\subsection{Agotamiento de la vía previa, plazo para impugnar y vía procedimental}

En teoría, frente a la actuación material o vía de hecho no corresponde la impugnación previa en sede administrativa, en la medida que respecto a la actuación material no existe procedimiento ni un acto administrativo alguno ${ }^{20}$.

El plazo para interponer la demanda contencioso administrativa argumentando esta pretensión, es de tres meses contados desde que el administrado tuvo

${ }^{20}$ HuAPAYA. op. cit. p. 864. 
conocimiento de la actuación material, tal como lo establece el artículo $19^{\circ}$, numeral 1, del TUO.

La vía procesal que se debe usar cuando se inicia el proceso contencioso administrativo planteando la pretensión de cese de una actuación material que no se sustente en acto administrativo, es la vía del "procedimiento" especial, tal como lo dispone el artículo $28^{\circ}$ del TUO.

\section{PRETENSIÓN DE CUMPLIMIENTO}

La pretensión mencionada se plantea frente a una inactividad de la administración. Es decir, presupone la omisión o el incumplimiento de la administración de una obligación establecida por ley o por acto administrativo.

En doctrina se ha distinguido entre inactividad formal e inactividad material. La inactividad formal se relaciona con el incumplimiento de la administración de su deber de pronunciarse sobre una solicitud o resolver una determinada situación jurídica; incluye dentro de sus alcances al silencio administrativo. La inactividad material por su lado, se entiende como la pasividad de la administración producida fuera de un procedimiento administrativo, supone siempre el incumplimiento, un dejar de hacer, de un mandato concreto contenido en una ley o un acto administrativo.

La inactividad material es la que puede ser discutida en sede judicial a través de la pretensión de cumplimiento, es decir, a través de la pretensión bajo comentario, la misma que se encuentra recogida en el artículo $5^{\circ}$, numeral $4^{\circ}$, de la Ley $27584^{21}$; dispositivo el cual señala que en el proceso contencioso administrativo podrán plantearse pretensiones con el objeto de obtener lo siguiente:

"4. Se ordene a la administración pública la realización de una determinada actuación a la que se encuentre obligada por mandato de ley o en virtud de acto administrativo firme."

Se ha dicho que esta pretensión presupone el incumplimiento de una obligación de la administración. Pero, concretamente ¿Qué persigue esta pretensión? Persigue que la autoridad jurisdiccional disponga u ordene a la administración que cumpla con su deber y realice efectivamente una actuación a la que se encuentra obligada. Es decir, se busca que el juez fuerce a la administración a adoptar un comportamiento. Generalmente le ordena

\footnotetext{
${ }^{21}$ En esta misma línea de opinión: HUAPAYA. op. cit. pp. 868 y siguientes.
} 
que cumpla con un hacer o un dar, pero también puede disponer que se abstenga de efectuar una acción contra los intereses del administrado.

Ahora bien, la obligación incumplida debe estar consignada en una ley o en un acto administrativo, y se exige para plantear la pretensión de cumplimiento que la actuación que debe realizar la administración sea clara, indubitable, concreta y que contenga un derecho atribuible a un determinado administrado. Estas son las condiciones de exigibilidad o ejecución de la conducta incumplida por la administración.

De otro lado, no podemos dejar desapercibida la vinculación existente ente la pretensión de cumplimiento, que se plantea en el proceso contencioso administrativo y la acción de cumplimiento que es un Proceso Constitucional.

Para exigir la prestación debida en el proceso de cumplimiento el Tribunal Constitucional en las sentencias correspondientes a los expedientes 191-2003AC/TC, 168-2005-PC/TC y otras, ha establecido determinados requisitos, entre ellos: 1) Que el mandato sea incondicional, 2) En caso sea condicional, que se acredite el cumplimiento de las condiciones, 3) Que el mandato sea cierto e indubitable, 4) Que tanto la ley o el acto administrativo que lo contienen deben encontrarse vigentes.

$\mathrm{Al}$ respecto, cabe precisar que estos requisitos son referenciales para examinar la pretensión de cumplimiento planteada en el PCA, en la medida que tales exigencias han sido establecidas para el proceso de cumplimiento que es un proceso que se usa como vía extraordinaria y que tiene características propias.

De otro lado, el juez, al evaluar la pretensión debe analizar la idoneidad del título, lo cual implica un examen de su validez y del cumplimiento de los requisitos para su exigibilidad. En el caso concreto del acto administrativo debe verificarse que se trate un acto firme, es decir, de un acto que ya no puede ser susceptible de recurso impugnatorio.

\subsection{Actuaciones contra las que se plantea}

La pretensión contenida en el artículo 5, numeral 4, de la ley 27584 puede plantearse contra las siguientes actuaciones:

a) La inercia de la administración pública (artículo $4^{\circ}$, inciso 2 , del TUO).

b) Las omisiones de la administración pública relativas a la contratación estatal (artículo $4^{\circ}$, inciso $5^{\circ}$, del TUO). 
c) Las actuaciones administrativas sobre el personal de la administración pública (artículo $4^{\circ}$, inciso $5^{\circ}$, del TUO) (entiéndase actuaciones en su acepción de omisión o inactividad).

En todos estos casos se planteará la pretensión de cumplimiento, solo si la inactividad o pretensión incumplida se encuentre contenida en una ley o un acto administrativo.

\subsection{Efectos en la sentencia}

Conforme a lo establecido en el artículo $41^{\circ}$, inciso 4, del TUO, el juez, de estimar la pretensión de cumplimiento, deberá disponer lo siguiente:

"El plazo en el que la administración debe cumplir con realizar determinada actuación a la que está obligada, sin perjuicio de poner en conocimiento del Ministerio Público el incumplimiento para el inicio del proceso penal correspondiente y la determinación de los daños y perjuicios que resulten el dicho incumplimiento."

\subsection{Agotamiento de la vía administrativa, plazo para impugnar y vía procedimental}

Cuando se plantea la pretensión de cumplimiento, la disposición contenida en el artículo $21^{\circ}$, numeral 2, exonera al administrado de la obligación de agotar la vía administrativa. En efecto, la indicada norma dispone:

"No será exigible el agotamiento de la vía administrativa en los siguientes casos:

4. Cuando en la demanda se formule como pretensión la prevista en el numeral 4 del artículo $5^{\circ}$ de esta Ley. En este caso el interesado deberá reclamar por escrito ante el titular de la respectiva entidad el cumplimiento de la actuación omitida. Si en el plazo de quince días a contar desde el día siguiente de presentado el reclamo no se cumpliese con realizar la actuación administrativa el interesado podrá presentar la demanda correspondiente."

El fundamento de presentar un reclamo o dirigirse previamente a la administración radica en el hecho de que ésta, ante la evidencia del mandato o la actuación debida, contenida en una ley o acto administrativo, pueda reflexionar, replantear su postura y decidir dar cumplimiento a lo ordenado en el título. 
De otro lado, tratándose de una inactividad o incumplimiento de la administración, la presentación de un reclamo no opera como un mecanismo de agotamiento de la vía administrativa, sino, estrictamente como un requisito de procedibilidad, esto es, como una condición para la iniciación del proceso.

Ahora, respecto al plazo para presentar la demanda que contiene esta pretensión, cabe señalar lo siguiente: Como el planteamiento de la pretensión de cumplimiento presupone inercia o inactividad de la administración, no corresponde computar plazo para interponer la demanda. Esta excepción al plazo general de tres meses resulta razonable pues no puede premiarse la inercia de la administración con la caducidad del derecho del administrado a iniciar un proceso contencioso administrativo por el incumplimiento de lo ordenado en una ley o un acto administrativo.

Al respecto, el artículo $19^{\circ}$ del $\mathrm{TUO}$, que incorpora las modificaciones operadas por el Decreto Legislativo 1067, dispone que la demanda deberá ser interpuesta dentro de los siguientes plazos:

3. Cuando se trate de silencio administrativo negativo, se observará lo establecido en el numeral 188.5 del artículo $188^{\circ}$ de la ley 27444 Ley del Procedimiento Administrativo General,... .22

Cuando se trate de inercia o cualquier otra omisión de las entidades distinta del silencio administrativo negativo, no se computará plazo para interponer la demanda."

La vía procesal que corresponde para tramitar la pretensión de cumplimiento es la del proceso urgente; así el artículo $26^{\circ}$ del TUO dispone que se tramita como proceso urgente únicamente las siguientes pretensiones:

“2. El cumplimiento por la administración de una determinada actuación a la que se encuentre obligada por mandato de la ley o en virtud de acto administrativo firme."

El fundamento de la tramitación urgente de esta pretensión, radica en que no existe discusión sobre la actuación que debe realizar la administración, ya que ella se encuentra contenida en una resolución firme o en un mandato legal. Siendo ello así, no hay razón para dilatar la tramitación, cuando lo

22 El numeral 188.5 del artículo 188.5 de la LPAG, dispone: "El silencio administrativo negativo no inicia el cómputo de plazos y términos para su impugnación". 
que corresponde es que la administración cumpla con su deber en un plazo breve.

Sin embargo, el Decreto Legislativo 1067 ha introducido algunas condiciones que deben cumplirse para tramitar la pretensión de cumplimiento en la vía de la tutela urgente. Así, el artículo $26^{\circ}$ en su tercer y cuarto párrafo dispone:

"Para conceder la tutela urgente se requiere que del mérito de la demanda y sus recaudos se advierta que concurrentemente existe:

a) Interés tutelable cierto y manifiesto,

b) Necesidad impostergable de tutela, y

c) Que sea la única vía eficaz para la tutela del derecho invocado."

Nótese que con la modificatoria operada, no todas las pretensiones que persiguen que se ordene a la administración la realización de una actuación a la que se encuentra obligada, podrán tramitarse en la vía del proceso urgente, pese a lo dispuesto en el numeral 2 del artículo $26^{\circ}$ del TUO. Solo se tramitarán en esta vía las que cumplan las condiciones arriba reseñadas. Tal como se encuentra redactada la norma, la revisión de tales condiciones se realizará al momento de calificar la demanda.

\section{PRETENSIÓN DE INDEMNIZACIÓN}

Como resulta previsible, la administración en el ejercicio de sus funciones puede causar daño a los administrados, y de hecho lo ha causado. Ante tal situación, la generalidad de los ordenamientos ha establecido la responsabilidad resarcitoria de la administración.

$\mathrm{Al}$ respecto, cabe anotar que este tema no ha estado adecuadamente regulado en nuestro ordenamiento, tanto en lo substancial como en lo procesal. Superando la legislación anterior, los decretos legislativos 1029 y 1067 han introducido una serie de modificaciones en la Ley del Procedimiento Administrativo General y en la Ley del Proceso Contencioso Administrativo, respectivamente, terminando de configurar un régimen más adecuado de las indemnizaciones atribuibles a la administración.

Las innovaciones del Decreto Legislativo 1067 han sido recogidas en el artículo $5^{\circ}$, numeral 5 , del TUO, el cual establece que en el proceso contencioso administrativo podrán plantearse pretensiones con el objeto de obtener lo siguiente: 
Percy Salas Ferro - Las pretensiones en el proceso contencioso administrativo

“5. La indemnización por el daño causado con alguna actuación impugnable, conforme al artículo $238^{\circ}$ de la Ley $N^{\circ} 27444$, siempre y cuando se plantee acumulativamente a alguna de las pretensiones anteriores."

Dentro del esquema estrictamente revisor de la actuación administrativa, no se integra por completo la institución a la indemnización. Por el contrario, el derecho al resarcimiento armoniza completamente con el principio de la tutela jurisdiccional efectiva y con la pretensión de plena jurisdicción. Dentro de este esquema, resulta lógico que frente a una actuación que le cause agravio al administrado, éste, no solo puede pretender que se reconozca y restablezca su derecho, sino también que la administración le indemnice por los daños generados.

El requisito procesal establecido para esta pretensión es que se plantee, no de manera autónoma, sino de manera acumulativa con las otras pretensiones contenidas en el artículo $5^{\circ}$ de la ley del PCA.

Los requisitos, condiciones, alcances y demás, del derecho a la indemnización, se encuentran regulados claramente en las Disposiciones Generales del artículo $238^{\circ}$ de la LPAG, cuyo texto es en el siguiente:

“238.1 Sin perjuicio de las responsabilidades previstas en el derecho común y en las leyes especiales, las entidades son patrimonialmente responsables frente a los administrados por los daños directos e inmediatos causados por los actos de la administración o los servicios públicos directamente prestados por aquéllas."

238.2 En los casos del numeral anterior, no hay lugar a la reparación por parte de la Administración, cuando el daño fuera consecuencia de caso fortuito o fuerza mayor, de hecho determinante del administrado damnificado o de tercero.

Tampoco hay lugar a reparación cuando la entidad hubiere actuado razonable y proporcionalmente en defensa de la vida, integridad o los bienes de las personas o en salvaguarda de los bienes públicos o cuando se trate de daños que el administrado tiene el deber jurídico de soportar de acuerdo con el ordenamiento jurídico y las circunstancias.

238.3 La declaratoria de nulidad de un acto administrativo en sede administrativa o por resolución judicial no presupone necesariamente derecho a la indemnización. 
Percy Salas Ferro - Las pretensiones en el proceso contencioso administrativo

238.4 EI daño alegado debe ser efectivo, valuable económicamente e individualizado con relación a un administrado o grupo de ellos.

238.5 La indemnización comprende el daño directo e inmediato y las demás consecuencias que se deriven de la acción u comisión generadora del daño, incluyendo el lucro cesante, el daño a la persona y el daño moral.

238.6 Cuando la entidad indemnice a los administrados, podrá repetir judicialmente de autoridades y demás personal a su servicio la responsabilidad en que hubieran incurrido, tomando en cuenta la existencia o no de intencionalidad, la responsabilidad profesional del personal involucrado y su relación con la producción del perjuicio. Sin embargo, la entidad podrá acordar con el responsable el reembolso de lo indemnizado, aprobando dicho acuerdo mediante resolución."

\section{RESUMEN - IDEAS FUERZA}

1. Existe estrecha vinculación entre la pretensión y las actuaciones impugnables. La pretensión presupone una actuación impugnable previa.

2. La pretensión es una declaración de voluntad fundamentada mediante el cual el administrado formula una petición concreta al órgano jurisdiccional con el propósito que éste ampare su postura frente a la administración. Por su incidencia en todo el desarrollo del proceso, la pretensión es el objeto del Proceso Contencioso Administrativo.

3. La pretensión de nulidad es la que tradicionalmente se ha planteado; sin embargo, incluso en la actualidad, se le reconoce y se usa intensivamente. Se plantea en base a causales tasadas de nulidad.

4. La pretensión de reconocimiento presupone la negación al administrado de un derecho que le corresponde. La pretensión de restablecimiento presupone una vulneración de un derecho ya reconocido. En estos casos, el juez puede adoptar las medidas que sean necesarias para efectivizarlas. Mediante estas pretensiones se puede impugnar todo tipo de actuaciones irregulares de la administración y persiguen la satisfacción plena de los intereses de los administrados. Se les conoce como pretensiones de plena jurisdicción y se inspiran en el principio de tutela jurisdiccional efectiva.

5. La pretensión de declaración de contrario a derecho y de cese de una actuación material que no se sustente en acto administrativo, se plantea 
Percy Salas Ferro - Las pretensiones en el proceso contencioso administrativo

frente a actuaciones típicamente arbitrarias de la administración que constituyen vías de hecho.

6. La pretensión de cumplimiento o de realización de una actuación por parte de la administración, presupone la existencia de un título (ley o acto administrativo) y ante la renuencia de cumplimiento se recurre ante el Poder Judicial.

7. La pretensión de indemnización se inspira en el principio de tutela jurisdiccional efectiva y constituye expresión de la pretensión de plena jurisdicción. Se plantea de manera acumulativa a otras pretensiones.

\section{CONCLUSIONES}

1. La pretensión procesal administrativa es una declaración de voluntad que se plantea ante un órgano jurisdiccional efectuando una petición concreta contra una actuación presuntamente irregular de una entidad pública, regulada por el derecho administrativo. Es una declaración petitoria fundamentada que se formula con el propósito que se ampare la postura del pretensor en relación a la controversia con la administración pública.

2. En torno a la pretensión, que consiste en una petición concreta que formula el pretensor, gira el desarrollo de todo el proceso (inicio, tramitación y culminación), razón por la cual se le concibe como el objeto del proceso contencioso administrativo.

3. El régimen de las pretensiones está inspirado en el Principio de la Tutela Jurisdiccional efectiva y en el criterio de plena jurisdicción. Por ello, se pueden impugnar todos los actos que afectan al administrado y se persigue la satisfacción plena de sus intereses.

4. Superando lo que ocurre en otros ordenamientos donde se reconoce solo la pretensión de nulidad y la pretensión de reconocimiento o restablecimiento, en el Perú se ha optado por establecer un elenco de pretensiones que, además de ellas, permite impugnar las actuaciones materiales ilícitas, la omisión o renuencia de la administración, y posibilita el otorgamiento de indemnizaciones.

5. No obstante la existencia de ese elenco de pretensiones, la pretensión de nulidad se encuentra plenamente vigente y es la que generalmente platean los demandantes para impugnar los actos de la administración. 


\section{CASOS PRÁCTICOS}

\section{CASO 01}

Durante los últimos años el gobierno y las autoridades del sector Energía se han planteado como objetivo extender el uso del gas natural hacia la zona norte de la ciudad de Lima.

En el marco de un programa creado para tal fin, se constituye el Consorcio Distribuidora de Gas del Norte y tiende sus redes a lo largo de los distritos de la zona norte de Lima, con el propósito de transportar y distribuir gas natural a las estaciones de servicios (gasocentros), viviendas y edificios residenciales que lo requieran.

Para controlar el transporte, regular el flujo del gas por cada uno de los ramales de distribución y, programar el suministro de gas a cada gasocentro, vivienda o edificio en particular, el Consorcio ha establecido una Estación de Control de Operaciones, en el distrito de San Martín de Porres.

Durante el año 2011, como consecuencia de sus operaciones, se han producido una serie de irregularidades técnicas y deficiencias de seguridad, entre ellas: 1) Fugas leves pero permanentes en los ductos contiguos a los gasocentros, 2) Falta de suministro del gas, 3) Cuatro incendios de mediana envergadura, 4) Denuncias permanentes de contaminación por parte de los vecinos residentes en inmediaciones de la estación de control.

Ante ello, el 12 de marzo del 2012, el OSINERGMIN, Organismo Supervisor de la Inversión Privada en Energía y Minería, con el propósito de remediar inmediatamente las irregularidades, interviene de manera intempestiva a la estación de control del Consorcio, cierra las válvulas de control e impide el flujo del gas hacia las estaciones de servicios, viviendas y edificios subministrados, argumentando que su labor primordial es garantizar la seguridad, atender inmediatamente las denuncias de los vecinos y superar de manera rápida y efectiva las irregularidades que se presenten en el transporte y distribución de gas natural. En el momento de la intervención los funcionarios del organismo regulador informaron al responsable de la estación de control que en el plazo más breve formalizarían su actuación y expedirían los documentos que la respaldan.

Como consecuencia de la intervención, el Consorcio incumple una serie de contratos de suministro con los gasocentros, viviendas y edificios subministrados, lo cual evidentemente le genera enormes pérdidas económicas y diversos tipos de agravios. 
Atendiendo a las particularidades del caso, responde las preguntas que líneas abajo se formulan.

\section{Preguntas guía}

1. ¿Es el OSINERGMIN el organismo competente para supervisar las actividades de distribución y comercialización de gas natural?

2. ¿Cuándo se considera que una actuación de la administración es arbitraria?

3. Ante las irregularidades detectadas y denuncias efectuadas ¿Puede el OSINERGMIN intervenir de manera intempestiva la estación de control del Consorcio, subsanando con posterioridad la emisión de la documentación que respalda su actuación?

4. ¿Qué acción judicial podría interponer el Consorcio, de considerar que la intervención fue irregular y lo agravia?

5. ¿Cuál de las pretensiones recogidas en el artículo 5 de la ley 27584, tendría que plantear si decidiera interponer una acción judicial?

6. ¿Cómo tendría que haber procedido OSINERGMIN en el presente caso?

\section{CASO 02}

Medical Importation es una empresa que se dedica a la importación y comercialización de equipos médicos. En marzo del 2011, efectúa su declaración anual del impuesto a la renta y considera en el rubro de deducciones el monto de \$ 240.000.00 correspondientes al valor de la mercadería que le había sido hurtada del almacén en el que la mantenía. Efectúa tal deducción con el propósito de disminuir su base imponible y, consecuentemente, abonar un monto menor por concepto de impuesto a la renta.

Luego de un proceso de fiscalización documentaria, la SUNAT considera que la deducción efectuada por la empresa no correspondía, porque no se ha cumplido con los requisitos y formalidades establecidas para tal efecto. Como consecuencia de ello, procede a emitir una resolución de determinación en la que se dispone que la empresa debe pagar la suma de \$ 60.000.00 adicionales por el impuesto a la renta.

Frente a tal determinación, Medical Importation interpone un recurso de reclamación ante la SUNAT, entidad que mediante Resolución $\mathrm{N}^{\circ}$ 001798-2011-SUNAT/OR declara infundado el recurso considerando que no procedía la deducción efectuada. Luego, ante la apelación plateada por la empresa, el Tribunal Fiscal confirma la resolución emitida por la SUNAT y señala que el monto que debe pagar la empresa es \$60.000.00. 
Habiendo agotado la vía administrativa, la empresa decide interponer una demanda contencioso administrativa ante el Poder Judicial.

\section{Preguntas guía}

1. ¿Qué se entiende por actuación impugnable? ¿Identifique cuál es la actuación impugnable en el caso propuesto?

2. ¿Cuál es el derecho en conflicto en el caso propuesto?

3. ¿Cuándo se plantea la pretensión de nulidad de un acto administrativo y cuándo la pretensión de reconocimiento?

4. ¿Son incompatibles las pretensiones de nulidad y de reconocimiento de un derecho?

5. ¿Cuál es la pretensión que tendría que invocar la demandante? ¿La pretensión de nulidad de la resolución administrativa o la pretensión de reconocimiento de un derecho?

\section{CASO 03}

HP Computer es una empresa dedicada al desarrollo de sistemas y módulos informáticos. Participa intensivamente en concursos públicos de proveedores para entidades estatales. En el concurso convocado por el Ministerio de Energía y Minas para el diseño de un sistema de gestión y seguimiento documentario, obtiene la buena pro; hecho que se formaliza mediante resolución del representante de la entidad y la firma del contrato.

Cuando luego de 45 días la empresa ganadora se dispone a iniciar los trabajos, el Ministro recientemente nombrado le señala que el otorgamiento de la buena pro y declaratoria de su condición de ganador fueron hechas por funcionarios de la gestión anterior y por lo tanto no puede iniciar trabajos, impidiéndole el acceso a la sede el Ministerio.

Ante tal situación de HP Computer, considerando que tal hecho le genera pérdidas, se formulan las siguientes interrogantes:

\section{Preguntas guía}

1. ¿Qué derechos se derivan para la empresa ganadora de la buena pro?

2. ¿Cuáles son las obligaciones de la entidad adjudicante?

3. ¿Qué actuación de la administración debe impugnar?

4. ¿Cuál o cuáles son las pretensiones que puede plantear conforme a la legislación vigente?

5. ¿Qué medidas concretas tendría que dictar el juez en una eventual sentencia estimatoria? 


\section{BIBLIOGRAFÍA}

Calamandrei, Piero. Instituciones de Derecho Procesal Civil. Vol. I. (Traducción de la segunda edición italiana por Santiago Sentís Melendo). Buenos Aires: Ediciones Jurídicas Europa América, 1962.

CONGReso De la RepúblicA. Exposición de Motivos del Proyecto de Ley que Regula el Proceso Contencioso Administrativo. Diario Oficial "El Peruano", edición del 05/07/2001.

Devis Echandía, Hernando. Nociones Generales de Derecho Procesal Civil. Madrid: Aguilar, 1966.

GuAsP, Jaime. Derecho Procesal Civil. $4^{\mathrm{a}}$ ed. Tomo I. Revisada y actualizada a la legislación vigente por Pedro Aragonés. Madrid: Civitas, 1998.

GonzÁlez PÉrez, Jesús. Manual de Derecho Procesal Administrativo. $3^{\mathrm{a}}$ Ed. Madrid: Civitas, 2001.

Hinostroza Mínguez, Alberto. Proceso Contencioso Administrativo. Lima: Grijley, 2010.

Huapaya Tapia, Ramón. Tratado del Proceso Contencioso Administrativo. Lima: Jurista Editores, 2006.

Normas Legales. Guía Práctica de Impugnación Judicial de Acciones Administrativas. Lima: Gaceta Jurídica, 2009.

Monroy GÁlvez, Juan. La Formación del Proceso Civil Peruano. $3^{\text {a }}$ ed. Lima: Comunitas, 2010.

Montero ArocA, Juan; GÓmez ColOMER, Juan; MONTÓn RedONDO, Alberto y Silvia BARONE VILAR. Derecho Jurisdiccional I. $17^{\mathrm{a}}$ ed. Valencia: Tirant lo Blanch, 2009.

PAlacio, Lino. Manual de Derecho Procesal Civil. 14 ${ }^{\mathrm{a}}$ ed. Buenos Aires: AbeledoPerrot, 1998.

Perrino, Pablo. La pretensión Procesal Administrativa como Objeto del Proceso Contencioso Administrativo. En Juan Carlos CASSAGNE (Dir.), Tratado de Derecho Procesal Administrativo, Tomo I, (pp. 409-436). Buenos Aires: La Ley, 2007.

PeYrano, Jorge. Derecho Procesal Civil de Acuerdo al C.P.C. Peruano. Lima: Ediciones Jurídicas, 1995. 